\title{
LITERATURA DE CORDEL E DIGNIDADE HUMANA: UMA INOVAÇÃO EDUCATIVA NO ATENDIMENTO A ALUNOS COM COMPORTAMENTO SUPERDOTADO ${ }^{30}$
}

\author{
CORDEL LITERATURE AND HUMAN DIGNITY: AN EDUCATIONAL \\ INNOVATION IN ATTENDING STUDENTS WITH GIFTED BEHAVIOR
}

\author{
Sonia Regina Alves Nogueira ${ }^{31}$ \\ Ursulla Herdy Gomes ${ }^{32}$ \\ Fernanda Serpa Cardoso 33 \\ Alice Akemi Yamasaki ${ }^{34}$
}

\begin{abstract}
Resumo
Neste trabalho, discorremos sobre a Oficina Interativa "Vida e Dignidade Humana rimadas em Cordel", realizada com alunos superdotados da Educação Básica, oferecida como atividade suplementar e de inclusão escolar, em ambiente universitário federal. Criada e aplicada através de metodologia inovadora, a oficina visou promover a dignidade humana, contextualizando suas reflexões nos tempos de exceção e na veiculação da cultura de ódio, em especial com as práticas identificadas de bullying pelos alunos e nos preconceitos tecidos acerca da cultura nordestina. A participação dos alunos em práticas colaborativas de leitura e escrita criativa, corroborou a vocação para a reflexão e criação literária insurgentes, evidenciando a contribuição da atividade para a ampliação dos capitais sociais.
\end{abstract}

\footnotetext{
30 Trabalho parcialmente apresentado no V Seminário Internacional de Inclusão em Educação Universidade e Participação: inclusão, interculturalidade e inovação pedagógica, Rio de Janeiro, 2019.

${ }^{31}$ Doutora em Física (Centro Brasileiro de Pesquisas Físicas). Professora Associada do Instituto de Química da UFF. Coordenadora do Grupo de Pesquisa e Extensão DIECI UFF. Membro pesquisadora do OIIIIPE UFF. E-mail: sranogueiradesa@gmail.com ORCID: https://orcid.org/0000-0002-9381-6548.

${ }^{32}$ Graduada em Letras/Literaturas pela UFF. Mestranda em Estudos de Literatura - UFF. Colaboradora do Grupo de Pesquisa e Extensão DIECl UFF. Professora da educação básica. E-mail: ursullagomes.herdy263@gmail.com ORCID: https://orcid.org/0000-0002-3154-6984.

33 Doutora em Ciências e Biotecnologia pela UFF. Professora Adjunta do Instituto de Biologia da UFF. Docente do Mestrado Profissional em Diversidade e Inclusão da UFF. Membro do Comitê Científico do ConBrASD. Coordenadora da Escola de Inclusão da UFF. Vice-coordenadora do Grupo de Pesquisa e Extensão DIECI UFF. E-mail: fernandalabiomol@yahoo.com.br ORCID: https://orcid.org/0000-0003-38061725 .

34 Doutora em Educação (USP). Professora Associada da Faculdade de Educação da UFF. Docentecolaboradora do Mestrado Profissional em Diversidade e Inclusão. Pesquisadora do Grupo de Pesquisa e Extensão DIECI UFF. Pesquisadora do OIIIIPE - UFF. E-mail: aayamasaki@id.uff.br ORCID: https://orcid.org/0000-0002-6449-5132
} 


\title{
RevistAleph
}

Palavras-chave: Inclusão. Inovação. Comportamento superdotado. Formação de professores.

\begin{abstract}
In this paper we talk about the Interactive Workshop "Life and Human Dignity rhymed in Cordel", held with gifted students of Basic Education, offered as a supplementary and school inclusion activity in a federal university environment. Created and applied through innovative methodology, the workshop aimed to promote human dignity, contextualizing its reflections in times of exception and in the dissemination of the hate culture, especially with the practices of bullying identified by students and in the prejudices woven about Brazilian Northeastern culture. The participation of students in collaborative reading and creative writing practices corroborated the vocation for insurgent reflection and literary creation, highlighting the activity's contribution to the expansion of social capital.
\end{abstract}

Keywords: Inclusion. Innovation. Gifted behavior. Teacher training.

\section{Introdução}

Educação inclusiva e inovação em educação são expressões frequentemente encontradas em estudos teóricos que discutem o ensino/educação neste século XXI; contudo, parafraseando a filósofa espanhola Adela Cortina (2005, p. 171), "estes são temas que estão na moda, mas que não são atuais", visto que muito se fala a respeito, mas não são devidamente efetivados em práticas, apesar da demanda escolar. É fato que a popularidade de terminologias educativas não consiste numa real compreensão das mesmas, tampouco representa uma opção metodológica a ser desenvolvida e adotada no cotidiano escolar de forma contextualizada ao aluno.

O termo inovação, por exemplo, é um conceito, geralmente, associado a recursos pedagógicos, cujo desenvolvimento requer a adoção de tecnologias computacionais no processo de ensino-aprendizagem; porém, conforme pretendemos esclarecer, este é um grande equívoco. Inovação em Educação é um conceito relativamente recente na história. Seu surgimento remonta às décadas de 1950/60, em que os primeiros teóricos a conceituaram como um processo composto em etapas previsíveis, desde a gestação até a implementação e generalização do mesmo, conforme 


\section{RevistAleph}

Porter (1981). Inovação, naquele contexto, foi introduzida no cenário educacional permeada por estigmas positivistas, que encaravam no aprimoramento de capacidades individuais, os caminhos para o desenvolvimento tecnológico.

Para além dessas ponderações primeiras, o pedagogo contemporâneo Humberto Maturana (1983) analisa a Inovação Educacional entendendo-a como "colocar a experiência Educacional a serviço de novas finalidades" (p. 14). Ou seja, Inovação requer questionamento e reflexão acerca das finalidades da ação educacional. Concebe-se, assim, que Inovar em Educação exige que as finalidades sejam desenvolvidas e efetivadas, de fato, através da busca de novos meios que atendam e se adequem aos objetivos pedagógicos. Tais meios podem assumir diferentes naturezas, de maneira a adequarem-se às possibilidades de recurso da instituição ou do professor, podendo consistir em (re)descobertas de práticas ancestrais ${ }^{35}$ ou recursos artísticos, por exemplo.

A educação obrigatória para todas as crianças se originou na Prússia, atual Alemanha, e se prestava a formar cidadãos fiéis e obedientes ao Estado, característica com que se difundiu pelos estados absolutistas e permaneceu até a Revolução Francesa. A noção de que todos devem ser educados, com base nos ideais iluministas no século $\mathrm{XIX}$, passa pela demanda de mão de obra especializada para a indústria capitalista e culmina na organização institucional da escola para "atender a todos", assumindo a estrutura tal como a conhecemos: separação por níveis/idade, cujo avanço se constitui por domínio de conteúdos pré-estabelecidos pela Instituição etc. Este formato configura a padronização do ensino, visando alcançar uma educação de massa, estabelecendo a antítese da personalização (REIMERS, et al., 2017). Nesse contexto, públicos que demandam uma abordagem pedagógica diferenciada são marginalizados; entre eles, encontram-se os alunos com comportamento superdotado.

\footnotetext{
35 Termo usado como referência à dinâmica histórica do gênero textual cordel desde sua insurgência, que a torna uma prática milenar, a qual fora apropriada no contexto brasileiro como ferramenta de empoderamento e difusão de conhecimento, característica, cuja recuperação e apropriação educativa consiste na recolha de uma prática ancestral de resistência e luta contra opressão.
} 


\section{RevistAleph}

O psicólogo americano Joseph Renzulli (2014) aponta que pessoas com comportamento superdotado são as que apresentam simultaneamente três características: habilidade (geral ou específica) acima da média, alto nível de criatividade e alto nível de envolvimento com a tarefa, que não podem ser mensuradas apenas através do Quociente de Inteligência; e, chama atenção ao fato de a superdotação estar ligada tanto a fatores genéticos quanto a fatores ambientais. Daí sua escolha pela designação 'comportamento superdotado', cujo desenvolvimento pleno dependerá dos estímulos ambientais. Assim, o atendimento educacional adequado ao grupo é indispensável para um melhor desenvolvimento de suas capacidades e habilidades excepcionais, pois apresenta necessidade formativa que transcende aquela proporcionada pela escola regular, sobretudo, no método de ensino tradicional.

No Brasil, as políticas públicas voltadas a esse grupo, denominado alunos com Altas Habilidades ou Superdotação (AH/SD), remontam a década de 1970, quando pela primeira vez os superdotados foram citados como público-alvo da educação especial pelo Artigo 9o da Lei 5.692/71 (BRASIL, 1971):

Os alunos que apresentam deficiências físicas ou mentais, os que se encontram em atraso considerável quanto à idade regular de matrícula e os superdotados deverão receber tratamento especial, de acordo com as normas fixadas pelos competentes Conselhos de Educação.

Praticamente meio século depois, apesar de grandes avanços no sistema educacional, a noção a respeito das AH/SD ainda é muito equivocada e prejudicada por uma série de mitos (ANTIPOFF \& CAMPOS, 2010) e crianças e jovens com comportamento superdotado não estão recebendo educação que efetivamente atenda suas necessidades especiais (NICOLOSO \& FREITAS, 2002; VIRGOLIM, 2007; FREITAS \& PÉREZ, 2012; PÉREZ, 2018).

A exigência de promover políticas quanto à identificação e atendimento a alunos com AH/SD foi outorgada a partir da Lei 9394/96 (BRASIL, 1996). Desde então, os sistemas educacionais passaram a levar em conta a heterogeneidade deste grupo, 


\section{RevistAleph}

prescrevendo medidas reais de assistência. Contudo, ações efetivas de ampla contemplação, ainda, não são amplas, tampouco factuais, devido a muitos fatores que a comprometem. Entre estes se destacam: o parco entendimento deste fenômeno por parte dos educadores, assim como acerca da inteligência, e a variabilidade do próprio conceito de superdotação (PÉREZ, 2018). Ambos estão intimamente ligados e evidenciam, inclusive, a necessidade de ampliar medidas de contato entre esse público específico e professores em exercício e, principalmente, em formação profissional.

Esse grupo de alunado carece, conforme o exposto, de um atendimento personalizado, o que vai de encontro à padronização do ensino (RENZULLI, 2014). Para tanto, existem caminhos que podem ser adotados como abordagem metodológica e um desses caminhos é a Inovação. Incluir requer inovar, porquanto a atitude inovadora exige a formulação de novos meios para atingir os objetivos educacionais estabelecidos, conforme defende Maturana (1983) e tais meios são e devem ser escolhidos a partir do contexto discente, de modo que se desenvolva um ensino adequado à realidade ambiental e às particularidades e singularidades do educando.

Desta forma, o presente artigo apresenta reflexões acerca destas questões a partir da descrição da experiência de uma ação inclusiva, assumida por um grupo de pesquisa interdisciplinar de uma universidade pública e federal, de modo a destacar a estratégia planejada, desenvolvida e realizada em uma oficina de cordel. São reflexões oriundas do processo pedagógico envolvido em um curso de férias para alunos superdotados, em janeiro de 2019, que teve como objetivos: introduzir o artísticoliterário Cordel a alunos da Educação Básica; despertá-los para questões sociais, de modo a ensinar/aprender para a justiça, igualdade e democracia, em conformidade com a perspectiva da Educação em Direitos Humanos (CANDAU, 2012);

como também contribuir para o desenvolvimento da inteligência interpessoal (GARDNER, 2001) dos educandos. 


\section{RevistAleph}

\section{Inovar para incluir e humanizar: fortalecendo a Dignidade Humana em tempos de exceção}

O grupo de pesquisa interdisciplinar, cujas experiências aqui referidas foram formuladas, é composto por doutoras em Biologia, Física, Matemática, Educação e Química e atua na formação de professores articulando o intuitivo e difícil diálogo entre disciplinas, amparado em Fazenda (2002), que defende que a interdisciplinaridade é uma atitude que perpassa a intersubjetividade. A tentativa de confrontar e de conciliar olhares, a fim de ampliar o próprio, consiste num exercício de (con)vivência que constitui habitus, conforme Setton (2002), levando sujeitos a compreenderem a potência que há em articular a diferença, de modo que tudo o que é construído como saber também o é em prol do reconhecimento de valores humanos que se orientam para a defesa da dignidade humana (CANDAU, 2012).

Paulo Freire ressalta que a humanização e o respeito à dignidade humana são constantemente ameaçados pela opressão (FREIRE, 1987, p. 51). Em tempos de obscurantismo e de exceção, uma das grandes tragédias do ser humano moderno está em renunciar - sem o saber - à sua capacidade de decidir. São circunstâncias de negação de si e submissão à opressão e à exceção, na qual o ser humano não se reconhece como sujeito, rebaixando-se à condição de puro objeto. Por meio da negação da humanização de todos, a materialização da injustiça, da exploração, da opressão e da violência ocorrem em decorrência da ação das elites e classes dominantes (YAMASAKI, 2007, p. 146).

Para Freire (2003), roubar a humanidade de alguém é uma distorção da vocação do ser mais. Ele constata, em várias partes do mundo, que o homem simples é esmagado, diminuído, acomodado, convertido em espectador e passa a ser dirigido pelo poder dos mitos e ilusões que forças sociais poderosas criam para ele. De forma semelhante, alunos com comportamento superdotado vêm sofrendo exclusão e interdição de potencial de ser mais devido à mitologia que envolve o tema. 


\section{RevistAleph}

Entre outras forças ilusórias de nossos tempos, podemos mencionar as redes sociais, as fake news e as diversas disputas de narrativas que buscam recriar o mundo conservador, tirano, elitista e opressor dos tempos de exceção. Naqueles tempos (de Paulo Freire) e atualmente (nos nossos tempos), acompanhamos um conjunto de mitos que, voltando-se contra o ser humano, o destroem e o aniquilam. De teorias conspiracionistas até propaganda enganosa, o obscurantismo e o charlatanismo andam de mãos dadas nestes tempos conservadores, necrófilos e pandêmicos. Nesse sentido, o ser humano se vê tragicamente assustado, vivendo e admitindo silenciamentos dos tempos autoritários e de exceção, temendo a convivência autêntica e até duvidando de suas reais e concretas possibilidades, como ser histórico. Tal desumanização e óbice de amor permitem que este humano perceba apenas que os tempos mudam, sem reconhecer e sem refletir sobre a significação dramática dessa passagem, embora sofra a própria destruição e aniquilamento, mergulhado na cultura do ódio. Está mais inconscientemente imerso na realidade que emerso, reproduzindo modos de viver e se adaptar à veiculação incessante da necropolítica. Paulo Freire (2000, p. 131) denuncia as opressões e violências presentes na sociedade e no mundo partindo de suas andarilhagens por vários continentes, a começar da imposição ao exílio pela Ditadura Militar brasileira.

Essa perspectiva de construir saberes a partir da vivência acaba por impregnar a elaboração de práticas educativas oriundas deste contexto. Nesse sentido, há alguns anos, temos proporcionado espaços-tempos educativos de atendimento suplementar para estudantes identificados com comportamento superdotado, em formato de Curso de Férias, ao longo das tardes de uma semana das férias de verão, e por três dias inteiros das férias de inverno. As atividades oferecidas são desenvolvidas e aplicadas em conjunto com licenciandos (aqui designados oficineiros) de diferentes cursos de licenciatura (Ciências Biológicas, Cinema, Filosofia, Física, Letras - Literatura, Matemática e Química) promovendo a formação inicial dos futuros professores para a educação inclusiva dos superdotados, bem como a convivência entre ambos os sujeitos. 


\section{RevistAleph}

Vale ressaltar que as ações pedagógicas desenvolvidas com os respectivos alunos nos cursos de férias visam não apenas o aprimoramento das faculdades intelectuais nas áreas de interesse, mas o estímulo à convivência e trabalho colaborativo em equipe, de modo a potencializar a inteligência interpessoal (GARDNER, 2001). Para tanto, em diversas ocasiões, a arte é evocada como horizonte de interlocução entre um conhecimento prescritivo e a subjetividade, de forma a promover a apropriação pelos alunos, em relação ao que é construído historicamente como saber.

Essa prática de inclusão, amparada em medidas de inovação (re)significa o que Freire (1987) concebe como Educação Libertadora: aquela que proporciona ao educando vivências e ferramentas para o exercício da cidadania, que se principia com a consciência de seu ser e estar no e com o mundo (FREIRE, 2000) e sua relação reflexiva e atuante no mesmo. $\mathrm{O}$ ato de Educar para a Liberdade requer, por conseguinte, que $\mathrm{O}$ conhecimento a ser construído seja contextualizado ao aluno. Tal modo de fazer (CERTEAU, 1994) dialoga com as premissas estabelecidas por Morin (2000) no que condiz com as demandas educativas para o século XXI, visto que os alunos deste século não podem ser educados tal como o eram há tempos.

Dessa forma, a atividade sobre a qual este texto se debruça, foi planejada como uma iniciativa de Educação Inovadora, porquanto inovar em educação significa adaptar a metodologia utilizada, assim como os conhecimentos abordados, à demanda discente, o que requer a investigação, por parte do educador das peculiaridades que compõem a heterogeneidade de uma sala de aula. Com essa compreensão, o educador poderá construir um ambiente educativo que inclua a todos, considerando suas peculiaridades

como sujeitos, característica da efetiva prática de uma educação libertadora. A educação libertadora, que por si mesma é inovadora, possibilita a inclusão, desde que a motivação que a oriente seja construir um ambiente educativo interativo, que busque desenvolver os alunos para além dos conteúdos disciplinares, construindo com eles conhecimentos pertinentes que promovam consciência cidadã e valores humanos, conforme orienta o Paradigma Científico Emergente (SANTOS, 2009). 


\section{RevistAleph}

A consciência acerca do público com o qual se trabalha possibilita o desenvolvimento de alternativas viáveis que vão ao encontro de questões particulares dos alunos, reconhecendo-se situações em que os mesmos se encontram imersos, de modo que o conhecimento COM eles construído toma como ponto de partida elementos que integram seus campos de referência. Por conseguinte, a oficina interativa (OI) promove a emersão diante de sua realidade, capacitando-os de modo que o debate e a reflexão coletiva propiciem caminhos que permitam a ela reimergir, propondo-se soluções para as situações analisadas munidos do conhecimento conquistado (FREIRE, 1987). Assim, o reconhecimento discente aliado ao trabalho reflexivo e colaborativo de conhecimentos adequados aos alunos na sala de aula proporciona uma prática pedagógica libertadora.

Para que as oficinas interativas oferecidas nos cursos de Férias para alunos superdotados alcancem o caráter que consideramos inovador, essas características são sempre levadas em conta durante o processo de criação. Este se desenvolve a partir do recolhimento das informações que respondem a cinco perguntas basilares: "Para quem?”, “O quê?”, "Por quê?", “Quando?” e “Onde?”. Através delas é possível planejar um atendimento contextualizado, cuja metodologia se adeque ao educando, conforme discutimos a seguir (NOGUEIRA et. al., 2020b).

\section{Oficina interativa de cordel: o percurso criativo entre os valores humanos e a inovação educacional}

O "Para quem?" é a pergunta introdutória no desenvolvimento de uma oficina interativa e exige o reconhecimento do público com quem se lida. É um aspecto fundamental para uma perspectiva humanista diante de um processo de elaboração pedagógica dialógica, visto que é a partir do e com o aluno que os saberes são construídos numa prática pedagógica problematizadora (FREIRE, 1987; NOGUEIRA et. al., 2020b). Isso é essencial não apenas em práticas de atendimento a um público 


\section{RevistAleph}

específico, como é o caso da oficina interativa de Cordel, mas em toda e qualquer sala de aula, afinal, em qualquer espaço educativo há diversidade e toda diversidade requer ser atendida respeitosa e dignamente. O processo de elaboração da oficina "Vida e dignidade humana rimadas em Cordel" teve início com um estudo para o reconhecimento dos estudantes que dela participaram, um grupo heterogêneo de 28 crianças com comportamento superdotado, cujas idades variavam entre 07 e 17 anos, e apenas quatro participantes eram meninas. Os pais, ou responsáveis, assinaram um Termo de Consentimento Livre e Esclarecido, sendo mantido o sigilo da identidade de todos. São alunos provenientes de classe socioeconômica baixa até classe média alta e apresentam comportamento superdotado em diferentes tipos de inteligência (GARDNER, 2001), entre as quais inteligência interpessoal, lógico-matemática, linguística, sinestésica e musical.

"O quê?" Trabalhar com esses alunos é a pergunta seguinte a qual os oficineiros, no processo de planejamento, se propõem a responder, conforme a demanda e a experiência com esse grupo discente em atividades anteriores. Nesse sentido, escolhemos valorizar e trabalhar o Cordel, de modo a resgatar funções primárias deste gênero literário no Brasil, somado ao desenvolvimento de um trabalho educativo de problematização e de expressão textual, que promovam uma reflexão crítica sobre o combate ao preconceito e à desigualdade social. Passamos por um período de revisão e aprofundamento de estudos acerca do tema da literatura de Cordel, a fim de selecionar quais conteúdos relacionados atenderiam as demandas que os próprios alunos apresentaram. Optamos, por conseguinte, trabalhar noções estruturais de uma literatura de Cordel, como conteúdo, conhecimento e saber, de modo a desafiar os alunos a produzirem um cordel autoral, em que deveriam versar sobre alguma vivência de manifestação de preconceito.

Por sua vez, o "Por quê?" foi justificado pelo reconhecimento de que os alunos com comportamento superdotado sofrem, majoritariamente, bullying na escola por 


\section{RevistAleph}

parte de colegas e, sobretudo, de professores (PEREZ, 2018); daí, temos constatado que esses estudantes apresentam empatia diante de atividades do curso de férias que permitam ou estimulem o repúdio e o combate a preconceitos estigmatizados no corpo social. Além disso, os próprios alunos, em uma oficina oferecida na edição do ano anterior do curso, solicitaram que o tema sobre práticas de preconceito voltasse a ser discutido entre eles, nas atividades dos cursos de férias. Assim, essa proposta de trabalho representou uma tentativa de conciliação entre discussões solicitadas pelos próprios alunos e a urgência prevista pelas oficineiras e orientadoras, no que consiste em aplacar ou amenizar (pré) conceitos. O Cordel, um gênero literário desprestigiado, frequentemente referido de forma pejorativa, na região sudeste do país, como "coisa de nordestino", foi adotado como uma ferramenta educativa de combate de alunos superdotados ao status quo social.

Vale destacar que o atual contexto histórico, de conservadorismo político, tem trazido a público preconceitos culturais contra os grupos sociais identificados como nordestinos. Tal preconceito, na região sudeste, reproduz a histórica repugnância das classes abastadas com os grupos populares, ressaltando uma compreensão autoritária e elitista de sociedade. Episódios desse preconceito contra o povo nordestino tem alimentado parte dos discursos de ódio e tal acontecimento, à semelhança de exageros históricos conhecidos pela humanidade como os campos de concentração, deve ser problematizado no âmbito da atividade pedagógica, contribuindo para o Educar para Nunca Mais (CANDAU, 2013), uma das práticas da Educação em Direitos Humanos. Nesse sentido, é importante que o processo de formação de futuros educadores no ensino superior possa proporcionar práticas pedagógicas insurgentes, que permitam indicar possibilidades de refletir, debater e combater o preconceito e o desrespeito à dignidade humana.

Por fim, o “Quando?" e o “Onde?" São perguntas cujas respostas são complementares e fundamentais para a adequação da metodologia ao tempo (escolar, de vida dos estudantes e disponibilidade para a realização da atividade) bem como à 


\section{RevistAleph}

necessária infraestrutura nos espaços de sua realização. Segundo o que foi mencionado ao longo deste texto, a oficina interativa de cordel foi planejada para ser realizada no Curso de Verão, podendo ter duração máxima de quatro horas, no ambiente da universidade federal.

Após o reconhecimento dessas informações, o "Como fazer" assume fluidez e aponta o percurso na insurgência, visto que os dados básicos necessários para o planejamento de uma atividade contextualizada estão presentes. Com isso, as oficineiras a partir de estudos individuais, pesquisas, reuniões de orientação, confecção de materiais e simulações pedagógicas aprimoram a metodologia e os recursos utilizados na oficina (material multimídia, livretos de cordel, materiais motivadores impressos etc.).

É válido ressaltar que o aprimoramento e o aperfeiçoamento do procedimento didático das atividades planejadas e realizadas no contexto do referido grupo só são possíveis através da simulação pedagógica. Durante essa simulação, o planejamento de condução inicial é revisado com a aplicação da atividade, por parte das oficineiras ministrantes, para os demais licenciandos do grupo, no caso estudantes dos cursos de licenciatura em Biologia, Física, Filosofia, Letras, Matemática e Química. Alguns desses licenciandos atuaram como monitores ou como observadores durante a realização da oficina de cordel com os alunos com comportamento superdotado.

Esse procedimento de aprimorar e de ajustar o "Como Fazer" se revela muito propício no contexto de formação de professores, uma vez que o olhar dos licenciandos que participam da simulação como alunos, se desenvolve na efetiva prática de reconhecer e destacar melhorias possíveis diante de equívocos de abordagem dos ministrantes durante a simulação, com uma via empírica da prática da ação-reflexãoação. Com isso, ao mesmo tempo em que atuam como contribuintes, avaliando o procedimento didático e a ação pedagógica dos colegas ministrantes, a fim de torná-los mais adequados aos alunos que participarão da oficina, os licenciandos são estimulados

e desafiados, no que condiz ao contato com saberes de outra natureza e com 


\section{RevistAleph}

alternativas diferenciadas de planejamento e realização de oficinas interativas, adequadas ao tema abordado. Consiste, também, em uma opção didático-metodológica que pode ser, inclusive, contextualizada em atividades relativas às suas respectivas áreas de atuação. Ou seja, o olhar docente se desenvolve pelo exercício da crítica e, simultaneamente, as oficineiras ministrantes aperfeiçoam a condução da atividade, como também são estimuladas no tangente à sua formação como profissionais da educação. As avaliações pontuais e dialógicas dos demais permitem a apropriação dos recursos a serem utilizados na oficina, favorecendo o domínio didático da metodologia proposta. Esse movimento formativo da simulação pedagógica desenvolve a capacidade crítica de todos os futuros educadores, apurando o olhar para detalhes que, muitas vezes, passam despercebidos. Os licenciandos contribuem ativamente na medida em que percebem, sem perder de vista o todo, aspectos específicos e importantes para que a inovação educativa seja alcançada e possibilite educar para a liberdade.

Com a conclusão das várias simulações pedagógicas, a oficina assumiu uma configuração final que foi desenvolvida com os alunos: uma atividade planejada para ter três horas de duração, organizada em três etapas. Levando em conta que os alunos que frequentam o curso de férias devem não apenas ser estimulados em seu tipo de inteligência acima da média (GARDNER, 2001), mas também desafiados e provocados a exercitar a convivência e a cooperação, decidimos realizar três sessões simultâneas da oficina, com 10 alunos em cada sala. Visando intensificar a interação, a fim de estimular a inteligência interpessoal, e propiciar condições ambientais adequadas à composição do Cordel através de medidas de colaboração no cumprimento de desafios propostos na oficina, em todas as etapas, optamos por organizar os alunos em grupos de trabalho com dois, três ou quatro componentes, dependendo da atividade realizada. Além disso, considerou-se que os grupos deveriam ser heterogêneos em relação à faixa etária e ao conteúdo de inteligência em que apresentam habilidade acima da média, favorecendo uma interação diversificada. 


\section{RevistAleph}

O processo final de preparação ocorre quando a equipe estabelece como a oficina interativa será avaliada. Em geral optamos pela avaliação qualitativa, conforme Lüdke \& André (1986), assumida coletivamente com os oficineiros e monitores, atuando como observadores e participantes completos. São produzidas análises documentais individuais sobre as atividades executadas e este documento é compartilhado na reunião de avaliação com toda a equipe. Para tal produção, oficineiros e monitores foram orientados a registrarem em seus cadernos de campo para cada etapa se: (a) o andamento pedagógico proposto para as atividades foi suficiente para se atingir os objetivos iniciais; (b) os materiais disponibilizados despertaram interesse e consciência para os temas associados; (c) os alunos, realmente, participaram ativamente; (d) os alunos interagiram tanto com os colegas de grupos quanto com os demais da sala; (e) os alunos apresentaram dificuldade (e quais) para a construção de seus cordéis.

Para finalizar as considerações sobre o percurso criativo, é válido recuperar que as perguntas basilares são fundamentais e as escolhas das "respostas" estruturam a oficina interativa de cordel de modo a assegurar a efetiva inovação educacional que favoreça a ampliação do capital social dos alunos com comportamento superdotado. Importante destacar que esse processo de planejamento, que se encerra apenas com a avaliação reflexiva realizada posteriormente à execução da oficina, é o percurso de uma criação coletiva e que subsidia a formação de professores com experiências insurgentes. É um caminho que se faz ao longo da caminhada; é um percurso que busca valorizar e incorporar diferentes vozes que surgem durante o processo criativo. O exercício da humildade das oficineiras, acolhendo as recomendações e observações da(s) simulação(ões) pedagógica(s) efetiva(m) a insurgência, contrapondo-se à solidão do fazer docente presente na escola convencional. É importante que os futuros professores possam colher de seus processos insurgentes de formação docente práticas que confrontem os discursos hegemônicos conservadores, reconhecendo que outro mundo é possível, também na sala de aula, com inovação que valorize a humanização. 


\section{RevistAleph}

\section{Alunos com comportamento superdotado e a OI "Vida e Dignidade Humana rimadas em Cordel" em ação}

A Ol foi planejada visando criar um ambiente de estímulo à composição do Cordel e ao trabalho colaborativo. Nesse sentido, tanto a organização do espaço, quanto o planejamento das etapas que compõem a atividade foram distribuídas de modo a atender às especificidades dos alunos que dela participariam. As etapas da Oficina Interativa foram planejadas visando criar um ambiente de estímulo à composição do Cordel e ao trabalho colaborativo. Para tanto, as salas nas quais as sessões da oficina ocorreram, foram inicialmente arrumadas dispondo em grupos de três ou quatro alunos. Na sala A tivemos dois trios e um quarteto; nas salas B e C formamos três trios. Tal organização física das mesas de trabalho foi proposta de forma que todos os alunos em cada sala pudessem estabelecer contato visual; que os integrantes de um grupo pudessem discutir entre si, sem atrapalhar os demais; ler as suas percepções, e as dos colegas, à medida que estas fossem registradas no quadro (conforme a incitação das oficineiras ministrantes); e, acompanhar confortavelmente o material multimídia.

Essa configuração da sala se justifica para buscar proporcionar um ambiente dialógico, que facilita a percepção dos alunos acerca de um conteúdo específico trabalhado, a partir das diferentes contribuições e apontamentos dos mesmos. Ela contribuiu para a construção conjunta de um saber que foi enriquecido pela diversidade de olhares; e, para garantir que as duas primeiras etapas da oficina interativa fossem de encontro ao modelo tradicional de educação, de forma que o objeto de investigação não fosse, imediatamente, descrito ao aluno, mas fazendo com que um círculo de cultura (FREIRE, 2003) se estabelecesse através do diálogo e, com uma problematização reflexiva crescente, o objeto fosse assimilado, de modo que as conclusões do grupo fossem alcançadas com as questões lançadas pelas oficineiras e pelos alunos.

A primeira etapa, de reconhecimento de algumas das características estruturais do cordel e de alguns aspectos temáticos, ocorreu de modo que os padrões desse estilo 


\section{RevistAleph}

poético e os temas evocados fossem percebidos tacitamente durante uma leitura conjunta de um texto. Em resumo, optou-se por usar uma dinâmica colaborativa em que a oficineira procedeu à leitura das duas primeiras estrofes e os alunos foram escolhidos aleatoriamente para dar continuidade à leitura de um cordel metalinguístico enquanto, simultaneamente, buscavam reconhecer padrões e identificar aspectos temáticos no texto. Ao final da leitura, cada grupo organizou suas conclusões e apresentou à sala suas considerações, auxiliados pelos questionamentos feitos pela oficineira.

A leitura colaborativa foi a do texto "A importância do Cordel na comunicação", em septilha contendo 32 estrofes, de autoria de João Batista Melo (2012), cordelista nascido em Itabaianinha - SE e residente em Niterói - RJ, que expõe e vende suas obras nas feiras do Campo de São Bento, em Niterói, e no Centro Luiz Gonzaga de Tradições Nordestinas, no Rio de Janeiro - RJ. A participação seguiu num ritmo constante, indicando o engajamento dos alunos na leitura em voz alta. Alguns dos estudantes mais novos, apesar de atentos, demonstraram dificuldade na realização da leitura. Observouse que em alguns casos essa dificuldade também se apresentou na escrita. Em diálogo posterior, confirmou-se a falta de estímulo e ausência de atividades letradas para esses jovens em suas respectivas escolas. Essa "descoberta" é um indício de que, ao contrário do que comumente se pensa, alunos com comportamento superdotado não apresentam um bom desempenho em qualquer tipo de atividade (PÉREZ, 2003). Identificar as lacunas na formação e desenvolvimento dos vários tipos de inteligências desses jovens é um saber necessário aos docentes, pois permite enriquecer o conhecimento dos alunos superdotados, indo além de estimular apenas aquele(s) tipo(s) de inteligência em que possuem potencial acima da média.

Os grupos apresentaram empenho na identificação dos padrões rítmicos e dissertaram apropriadamente sobre aspectos temáticos textuais, dialogando com seus conhecimentos de história. Um dos alunos, que frequenta os cursos há três anos e é apaixonado por História, muito rapidamente decifrou a charada de que o Cordel se 


\section{RevistAleph}

tratava de uma Literatura oral oriunda da Europa. Surpreendia os adultos presentes que, com apenas 12 anos à época, o estudante apresentava um conjunto de detalhes expressando grande domínio de conteúdo específico para alguém da sua idade, descrevendo as nuances das navegações exploratórias, sobretudo, a portuguesa, associando-a como uma medida liberalista de expansão colonial decorrente do Humanismo. Tal característica é observada em alunos com comportamento superdotado, acerca de assuntos de seu interesse (RENZULLI, 2014).

Em todas as turmas, as discussões foram enriquecidas pelos apontamentos que os alunos apresentaram, mediante as incitações e provocações desafiadoras das oficineiras ministrantes. Em uma delas, um dos estudantes identificou alguns elementos interessantes, como o fato de a comunicação, de forma geral, aparecer em diversos momentos do texto lido e, portanto, o cordel teria uma relação muito forte com o diálogo entre culturas e pessoas. Outros ainda já tiveram, em ocasiões anteriores, contato com essa literatura e, por isso, sabiam que o próprio nome cordel era atribuído à forma como este era comercializado no Nordeste, assumindo e sendo reconhecido como um representativo aspecto cultural dessa região é um tema em potencial.

As características estruturais da literatura de cordel foram delimitadas (texto em versos, que se dispõem em estrofes, métrica, rima) a partir das observações do que os próprios estudantes pontuaram. O conhecimento literário que todos desconheciam é que o cordel é classificado pelo tipo de estrofe. Depois de várias tentativas de determinar o nome, declararam que "o spoiler" era necessário e apresentamos o nome septilha, como classificação daquele cordel. Assim, a primeira etapa da oficina interativa de cordel representou um desafio a ser superado por cada um dos estudantes, o que potencialmente os envolveu com a tarefa (RENZULLI, 2014): além de serem convocados a lerem, identificando padrões e elucidando temas, tiveram que, ao mesmo tempo, avaliar a leitura dos colegas e eleger, em cada turma, aquele que, segundo eles, procedeu à leitura mais fluída e mais "cordelesca". Os vencedores conquistaram o reconhecimento coletivo e o prêmio quase com unanimidade, sendo muito 


\section{RevistAleph}

comemorados e aplaudidos quando o receberam na reunião de encerramento do curso, indicando que cultivar a colaboração entre os estudantes superou qualquer possível competitividade, aspecto foi observado em todas as turmas.

A segunda etapa consistiu em desvendar e identificar as diferenças entre o cordel brasileiro e o lusitano. Para tal, foram selecionados cordéis de diferentes classificações e preparado um material multimídia, usando os recursos de animação do programa Power Point, em duas partes: a primeira contendo informações sobre a origem europeia desse gênero, sua vinda para o Brasil e as características da apropriação brasileira; e, a segunda, com estrofes de cada cordel selecionado dispostas paralelamente, indicando o número de versos (a classificação), a rima e o tema de cada um. É importante ressaltar que esse material multimídia não foi usado para apresentar as informações, e sim para sistematizar e expor as discussões e conclusões alcançadas pelos estudantes, daí também a importância do uso dos recursos de animação do Powerpoint.

A discussão, orientada na primeira parte do material multimídia, levou a percepção de que algumas características, sobretudo temáticas, diferiam o cordel lusitano do brasileiro e esses aspectos expressavam relação com a função social do gênero em cada contexto. A interrogativa, apresentada após o fechamento das conclusões, do que, enfim, diferia o cordel brasileiro do lusitano conquistou o interesse nas três turmas, motivando a participação na atividade seguinte, em que cada grupo trabalharia um dos cordéis selecionados, que diferiam no que consiste esfera temática e classificação, além de conter um traço característico da apropriação brasileira. Cada grupo deveria reconhecer padrões, identificar temas e ao final socializar com os demais colegas. Em todas as turmas, houve engajamento na tarefa, marcada por uma boa interação em equipe.

Foram usados os textos: "Seu João, a onça e o corujão" (MELO, 2000), em quadras - grupos 1; "Mariana" (ARRAES, 2017), em sextilhas- grupos 2; e, "O Cachoeira e o Espertão" e "Jovens acusados de agressão vão responder por tentativa de homicídio" 


\section{RevistAleph}

(FREITAS, 2012) com estrofes mistas, em sextilhas e septilhas - grupos 3. A identificação dos padrões rítmicos, a exemplo da primeira leitura, foi imediata em todos os grupos. A nomenclatura de classificação, que também foi sugerida pelos grupos, foi precisa, sendo os poucos erros referentes às quadras - alguns alunos sugeriram que o nome fosse "quadrilha", pois, segundo eles, faria mais sentido. O reconhecimento temático também foi perspicaz e muito bem descrito, com raras exceções, tratando-se de temas menos óbvios.

Em uma das turmas, o grupo 1 compreendeu a dinâmica narrativa, mas não soube definir o tema em uma palavra, tal como o desafio fora proposto. Essa dificuldade foi verificada em todos os grupos que trabalharam com esse cordel. Após refletirem com a oficineira, os alunos que o compunham rapidamente demonstraram muita articulação e segurança ao apresentar aos demais que, tratando-se de uma narrativa corriqueira um dos temas que ali se apresentavam era o prosaísmo, ou seja, qualidade do que é prosaico, comum, cotidiano. Um dos alunos acrescentou que, à maneira dos contos de fada medievais, aquele cordel aparentava alertar aos leitores, sobretudo as crianças, sobre os perigos que podem ser encontrados nas florestas e matos densos, só que de forma humorada e divertida.

De forma análoga, em um dos grupos 2, a identificação também não foi imediata, mas pela incitação feita conforme o modelo dedutivo (RENZULLI, 2014) concluíram que se tratava, nesse caso, de representatividade de um povo socialmente oprimido. Os demais grupos que trabalharam com cordéis noticiosos perceberam o teor jornalístico, mas também não souberam resumir em uma palavra. Foram incitados a relacionar suas percepções com palavra que tem relação com jornalismo e, depois de algumas discussões, chegaram à palavra "informatividade". Em todas as turmas, com a reunião do que cada grupo apresentou, a delimitação da apropriação brasileira foi feita, assim como os tipos conhecidos servindo de um possível modelo para a etapa seguinte.

A terceira etapa, em que os alunos exerceram a autoria a partir de temas estabelecidos, ocorreu após o intervalo para o lanche e teve uma duração equitativa à 


\section{RevistAleph}

primeira e segunda juntas, ou seja, uma hora e meia. Em todas as turmas os alunos foram reorganizados, resultando num total de onze duplas e dois trios, e sortearam um dos temas propostos: Mulheres na Ciência, Xenofobia contra Nordestinos, Homofobia, Inclusão de Deficientes Visuais e Bullying. Conforme dissemos, esses temas já haviam sido sinalizados pelos alunos no ano anterior, apenas o tema "Xenofobia contra Nordestinos" foi introduzido. A escolha desse tema ocorreu devido a uma onda de mensagens difamatórias contra essa região do Brasil, surgida na internet durante e após as eleições presidenciais de 2018, período em que o grupo de pesquisa recém encerrara uma série de estudos e reflexões a partir do livro "Eichmann em Jerusalém" de Hanna Arendt (1990), estando muito atentos às práticas de banalização do mal.

Para cada tema, os grupos que o sortearam receberam um conjunto impresso de notícias que o abordava, evidenciando a forma de preconceito correspondente aos grupos sociais marginalizados; os alunos foram desafiados a escrever um cordel a respeito no formato que desejassem. Ao todo foram produzidos treze cordéis. Entre eles: sete foram quadras, três foram sextilhas e três foram septilhas. A rima foi um elemento presente na maioria dos cordéis com apenas duas exceções e, além das rimas, três das produções apresentaram métricas regulares.

Todos os grupos demonstraram esforço em superar o desafio de compor, com raras exceções de desinteresse expresso, apenas, no quesito escrita. Mesmo nos três casos em que isso ocorreu, observamos a organização colaborativa característica de grupos de alunos com comportamento superdotado (RENZULLI, 2014), em que se organizam para cada um contribuir com sua capacidade em um projeto em grupo, pois enquanto um dos componentes compunha, o outro ilustrava a capa. Em uma dessas três duplas, um dos alunos era mais novo e recém alfabetizado e, logicamente, não apresentava familiaridade com a escrita. Ele disse que, em sua defesa, a ilustração da capa parecia muito importante no Cordel, visto que a xilogravura também era uma arte "cordelesca", por isso, nada mais justo que alguém se dedicasse para uma bela capa. Muitos se apropriaram da narratividade, inclusive os alunos mais jovens, do segundo 


\section{RevistAleph}

segmento do Ensino Fundamental, desenvolvendo uma história em que uma personagem é versada conotando uma forma de combate ao preconceito tangente ao grupo marginalizado que representa. Nos demais, o preconceito fora evocado poética e especulativamente ou em forma de relato pessoal, adequando-se, todavia, a lírica do cordel.

Além disso, vários cordéis produzidos assumiram uma dimensão realmente pessoal, uma vez que seus autores narraram sua própria vivência em rimas e estrofes padronizadas. As palavras não foram combinadas apenas como um jogo, mas como uma (re)significação do que o próprio viveu. Em um desses casos, um estudante de 12 anos narrou com detalhes uma trajetória de sofrimento como vítima de bullying na escola, por anos seguidos, recorrência que o levou a pensar em se suicidar. Porém, o aluno superdotado repensou, pediu ajuda à sua mãe e, com o apoio dos pais, estava superando essa situação. Como na reunião de confraternização são expostos todos os produtos dos alunos durante as oficinas, perguntamos se seu cordel deveria ser exposto com os demais, ele disse que em sua opinião era importante que o fosse. Consultados, os pais confirmaram o relato do adolescente e autorizaram a exposição. Esse caso mostrou a toda equipe, e alertou alguns dos pais, um efeito quase extremo da ignorância e dos mitos acerca das AH/SD (PÉREZ, 2003) e reafirma a importância e a urgência em modificarmos o cenário atual, tanto acerca da identificação quanto do atendimento a esse público.

\section{Análise e Avaliação}

Embora distintas, todas as etapas dessa oficina interativa convergem no sentido de se constituírem em metodologias ativas de caráter dialógico (BACICH E MORAN, 2018), apoiadas na problematização freiriana (FREIRE, 1987), em que os alunos exploraram as características estruturais da Literatura de Cordel, como também 


\section{RevistAleph}

investigaram a dinâmica histórica do gênero literário e as competências socioculturais próprias do Cordel brasileiro, além de exercitar a criatividade.

Em seu todo, por desafiar e estimular a busca por novos conhecimentos, a OI se constituiu em uma atividade do tipo III do Modelo Triádico de Enriquecimento de Renzulli (2014). As etapas, quando analisadas em interação, podem ser interpretadas tal como os momentos elucidados por Freire (1987) numa prática dialógica: a imersão, a emersão e a reimersão. Nesse sentido, na primeira e em parte da segunda etapa, os alunos foram imersos em uma realidade que, embora ainda inconscientes disso, é análoga à deles, pois esses jovens são familiarizados com a desigualdade e de certa forma com a opressão por uma peculiaridade que apresentam. Assim, à medida que mergulharam em um universo poético e descobriram as características, temas e propriedades do cordel, os alunos emergiram, assumindo consciência de sua condição compartilhada com outras pessoas e sua possibilidade de versar sobre injustiças, tal como muitos cordelistas fizeram e o fazem contemporaneamente. Os alunos com comportamento superdotado foram, por consequência, reimersos em sua realidade como autores que expressam sua voz na defesa de valores humanos que não são apenas seus, mas de todos, desenvolvendo-se e atuando, conforme aponta Renzulli (2002), como capitais sociais.

Isso foi consequência do próprio percurso criativo da Ol e, mais especificamente, do desenvolvimento da etapa de explicitação do "Por quê?", que permitiu externar a viabilidade de uma atividade dialógica e problematizadora que propiciasse uma ampliação do capital social dos alunos com comportamento superdotado, estimulando ação insurgente desses jovens. Como parte do exercício de emersão, a OI os desafiou a denunciarem as violações de Direitos Humanos, favorecendo uma desconstrução da imagem dominante do cordel na região sudeste, aliando a revisão do prestígio dessa literatura com uma produção autoral temática crítica que, na reimerção, contribuísse para a afirmação e a valorização desse gênero literário como expressão autêntica do povo nordestino. Assim, ao socializarem as várias produções literárias, deram 


\section{RevistAleph}

visibilidade às reflexões acumuladas sobre as vivências de bullying e assédio moral, às percepções sobre a invisibilização da mulher nas ciências e a homofobia, com o anúncio de outras possibilidades de convivência humana e demonstrando a riqueza da literatura de cordel e da cultura nordestina.

A confirmação do sujeito em sua humanidade é o caminho que performa o exercício de (ser)humano, que se realiza pelo (re)conhecimento de si no outro como um igual, apesar das diferenças que o compõe. Ao versar em cordel as temáticas propostas de repúdio ao preconceito, esses alunos, além de (re)formularem o seu ser e estar no e com o mundo (FREIRE, 1987), praticaram o que se espera de uma Educação baseada na perspectiva de Direitos Humanos (CANDAU, 2012): a formação de sujeitos de direito. Nesse sentido, ao tempo que se promove uma atividade através do cordel, um gênero textual previsto pelo Currículo do Estado do Rio de Janeiro (2012), em que se espera o reconhecimento temático e estrutural por parte dos alunos, suscita-se a seleção e mobilização desse conteúdo para uma perspectiva humana e social, não apenas proporcionando as competências do ensino formal, mas também e, principalmente, a consciência cidadã.

A estratégia adotada na OI dialoga com o que Renzulli (2014) defende ser apropriado no que condiz o desenvolvimento do comportamento superdotado, em que uma educação voltada a esse público se orienta a incitar os alunos a saírem da inspiração e partir para a ação, ou seja, transcender suas potencialidades, convertendo ideias e valores em ações práticas e efetivas, neste caso, em denúncia através de versos sobre dignidade humana. Nesse sentido, a terceira etapa da OI é a que representa a ação, porquanto nela os alunos exerceram a autoria que "é uma função do ser" (FOUCAULT, 2002). Ou seja, a consciência desses alunos que já se orienta no exercício cidadão de combate às desigualdades se fez diluída em versos de Cordel, com uma grande propriedade, visto que aquele gênero acabara de lhes ser apresentado.

Ressalta-se, finalmente, que acerca das questões propostas para avaliação da oficina, houve um consenso entre os observadores de que: (a) o andamento pedagógico 


\section{RevistAleph}

proposto atingiu os objetivos estabelecidos, efetivando seu caráter de inovação educacional; (b) os materiais confeccionados despertaram interesse e consciência para os temas associados, promovendo a ação insurgente por parte dos alunos; (c) a participação dos alunos foi ativa e colaborativa; (d) os alunos interagiram tanto com os colegas de grupos quanto com os demais da sala; e, (e) em três casos particulares, alunos apresentaram dificuldade de produção escrita e os mesmos contribuíram com a ilustração das capas.

Às oficineiras, o percurso criativo, a realização com os estudantes e a avaliação da oficina interativa possibilitou reconhecer que o tema da Inclusão envolve a reflexão sobre uma práxis pedagógica adequada aos alunos, ou seja, uma metodologia utilizada tendo em vista um contexto discente específico. O que implica em uma ação pedagógica dialógica que se realiza de modo a desenvolver a criticidade e emancipação dos alunos, cujo contraponto é a educação bancária. Também refletiram acerca da articulação entre inclusão, inovação, e Educação na perspectiva dos Direitos Humanos, e como esses elementos coordenados colaboram para complexificar o olhar do professor no que consiste à elaboração de atividades que apresentem tais peculiaridades e visem alcançar, de forma personalizada, um grupo específico. Vivenciaram o Educar para Liberdade, compreendendo-o como uma práxis que se realiza COM os alunos, de modo a incitar-Ihes a convivência com os demais do seu ciclo educacional, ou grupo. Fizeram uso de situações e conceitos do seu campo de referência, para promover nos alunos a consciência de estarem imersos em sua realidade e, juntos estudantes-oficinas, emergiram, apropriando-se de novos conhecimentos, como os relacionados à Literatura de Cordel e sua característica de denunciar desigualdades. De modo que os alunos colaborassem mutuamente para o desenvolvimento de seus olhares e percepções de forma a reimergirem através de ações para modificar o mundo. 


\section{RevistAleph}

\section{Considerações finais}

A estratégia adotada para a realização desta oficina interativa foi condizente para se atingir os objetivos propostos e a opção pela Literatura de Cordel demonstrouse muito adequada, pois, além de demandar um empenho na construção formal e rítmica do texto, exigiu dos alunos o reconhecimento do universo temático por eles poetizado que foram, intencionalmente, temáticas de violação à dignidade humana.

Essa tentativa, que se realiza em cultivar valores humanos, consolidou-se através da articulação entre conteúdos específicos e modalidades artísticas. Perspectiva que se revelou muito oportuna, porquanto ativou propriedades criativas inerentes a esses sujeitos ao mesmo tempo em que promoveu seu amadurecimento enquanto capitais sociais. A estratégia usada na OI contribuiu para o desenvolvimento da condição autora dos alunos, num formato poético-estrutural do cordel, desafiando-os a versarem sobre a dignidade negada a parcelas sociais e, por vezes, a eles mesmos quando não são devidamente incluídos e educados como deveriam na escola. Despertando-os, assim, para a consciência da negação imposta à sua própria humanidade, bem como à dos demais, impondo uma urgência de versar contra desigualdades como um primeiro movimento insurgente para modificar tais realidades.

Ao resgatar o contexto histórico adverso à defesa da vida que temos testemunhado, com a veiculação midiática da cultura de ódio em nosso cotidiano, intrafamiliar e escolar, expressando os tempos de exceção que reconhecemos, fomos desafiadas a aprofundar nossos conhecimentos acerca das experiências históricas que a humanidade já enfrentou. Nesse sentido, ainda imersas nas práticas diluídas e invisíveis de manipulação da população, com ações dispersas de preconceito, racismo, homofobia e intolerância religiosa, foi importante realizar o estudo acerca da banalidade sobre o mal. Tal estudo, relacionado aos debates teóricos acumulados sobre interdisciplinaridade, complexidade e ensino problematizador, mostraram-se férteis para o conjunto do grupo de pesquisa, de forma que foi possível exercitar coletivamente 


\section{RevistAleph}

o percurso criativo inédito dessa OI, uma vez que inserirmos a literatura de cordel entre os conhecimentos a serem trabalhos nas Ol desenvolvidas por um grupo de pesquisa na área das Ciências da Natureza. Sem dúvida, contribuiu para este feito, o trabalho realizado em curso de férias, anteriormente ao momento relatado neste artigo, com os pais e alunos com comportamento superdotado, que debateu sobre a dignidade humana. Naquele momento, as pesquisadoras e autoras deste artigo introduziram a reflexão sobre o Direito à Educação, a importância da Educação em Direitos Humanos e todas as implicações destas para a compreensão sobre o respeito à dignidade humana, desenvolvendo diretamente a atividade em dois grupos. O diálogo com os pais e com os alunos com comportamento superdotado permitiu subsidiar os passos seguintes, uma vez que, de diferentes níveis, o tema da dignidade humana foi introduzido na comunidade. Com isso, a inovação educativa e a ação pedagógica insurgente possibilitaram que a formação de professores de todo o grupo de pesquisa se tornasse uma possibilidade de criação coletiva diante de problemas sociais graves, notadamente de violação de direitos.

Assim, amparadas em subterfúgios históricos, que evidenciam o Cordel como uma literatura de empoderamento de classes sociais desfavorecidas, e assentadas sobre uma metodologia que repousa na intersubjetividade, na Educação Libertadora e nos princípios da complexidade, aliamos uma prática social milenar que, através do gênero literário cordel, combatia a desigualdade, de modo a, contemporaneamente, fazer o mesmo em relação a grupos específicos. Dessa forma, o cordel, tão antigo e desconhecido ou considerado ultrapassado pela maioria dos nascidos no século XXI, foi utilizado com sucesso como uma ferramenta de inovação, visando à inclusão de alunos com comportamento superdotado, que como os demais educandos, demandam um atendimento personalizado. Consideramos que essa estratégia inovadora pode ser adaptada e usada em qualquer espaço-tempo de aprendizagem. Por fim, nunca será demasiado lembrar que esse tipo de atuação pedagógica e estratégia de aprendizagem só se realiza à luz do Paradigma Educacional e Científico Emergente. 


\section{RevistAleph}

Referências

ANTIPOFF, Cecília Andrade; CAMPOS, Regina Helena de Freitas. Superdotação e seus mitos. Psicologia Escolar e Educacional, [S.L.], v. 14, n. 2, p. 301-309, dez. 2010. Disponível em: https://www.scielo.br/pdf/pee/v14n2/a12v14n2.pdf. Acesso em: 10 fev. 2020.

ARRAES, Jarid. Heroínas negras brasileiras em 15 cordéis. São Paulo: Pólen, 2017.

BACICH, Lilian; MORAN. José. (org.). Metodologias ativas para uma educação inovadora: uma abordagem téorico-prática. Porto Alegre: Penso, 2018.

BRASIL. Lei n. 9.394 de 20 de dezembro de 1996. Estabelece as diretrizes e bases da Educação Nacional. D.F. Ministério de Educação e Cultura. Brasília.

BRASIL. Lei n. 5.692, de 11 de agosto de 1971. Fixa Diretrizes e Bases para o ensino de $1^{\circ}$ e $2^{\circ}=$ graus e dá outras providências. D.F. Ministério de Educação e Cultura. Brasília.

CANDAU, Vera Maria. Educação em direitos humanos no Brasil: gênese, desenvolvimento e desafios atuais. In: PAIVA, Angela Randolpho. (Org.) Direitos humanos em seus desafios contemporâneos. 1 ed. Rio de Janeiro: Pallas, 2012. p. 17-34.

CERTEAU, Michel. A invenção do cotidiano I: as artes do fazer. Petrópolis: Vozes, 1994.

CORTINA, Adela. Educar na cidadania. Aprender a construir o mundo juntos. In: CORTINA, Adela. Cidadãos do Mundo - Uma teoria da cidadania. São Paulo: Loyola, 2005. p. 171 - 197.

FAZENDA, Ivani Catarina Arantes. Integração e interdisciplinaridade no ensino brasileiro: Efetividade ou Ideologia? 5. ed. São Paulo: Edições Loyola, 2002.

FREIRE, Paulo. A pedagogia do oprimido. Rio de Janeiro: Paz e Terra, 1987.

FREIRE, Paulo. Educação como prática da liberdade. Rio de Janeiro: Paz e Terra, 2003.

FREIRE, Paulo. Pedagogia da indignação: cartas pedagógicas e outros escritos. São Paulo: Ed. UNESP, 2000.

FOUCAULT, Michel. O que é um autor? Portugal: Veja/Passagens, 2002.

FREITAS, Soraia Napoleão; PÉREZ, Susana Graciela Pérez Barrera. Altas

Habilidades/Superdotação: atendimento especializado. 2. ed. Marília: ABPEE, 2012. 


\section{RevistAleph}

FREITAS, Willian. 0 cachoeira e o espertão. Notícia em cordel. Disponível em: https://noticiaemcordel.wordpress.com/2012/06/09/o-cachoeira-e-o-espertao/. Acesso em: 03 mar. 2020.

FREITAS, Willian. Jovens acusados de agressão vão responder por tentativa de homicídio. Notícia em cordel. Disponível em: https://noticiaemcordel.wordpress.com/2012/02/05/7/. Acesso em: 03 mar. 2020.

GARDNER, Howard. Inteligência: um conceito reformulado. Rio de Janeiro: Objetiva, 2001.

LÜDKE, Menga; ANDRÉ, Maria Eliza Dalmazo Afonso de Pesquisa em educação: abordagens qualitativas. São Paulo: EPU, 1986.

MELO, João Batista. A importância do cordel na comunicação. Niterói: [S.N.] 2012. Literatura de Cordel.

MELO, João Batista. Seu João, a onça e o corujão. Niterói: [S.N.] 2000. Literatura de Cordel.

MATURANA, Humberto. Fenomenologia del conocer. Revista de Tecnologia Educativa. [S.L.] v.8, n. 3/4, p. 228-252, 1983.

MORIN, Edgar. Os Sete Saberes necessários à Educação do Futuro. São Paulo: Cortez, 2000.

NICOLOSO, Cláudia Maria Ferreira; FREITAS, Sônia Napoleão A escola atual e o atendimento aos portadores de altas habilidades. Revista Educação Especial. Santa Maria - RS n. 9, p. 11-14. 2002. Disponível em: https://periodicos.ufsm.br/educacaoespecial/article/view/5127. Acesso em: 09 mar. 2020.

NOGUEIRA, Sonia Regina Alves; CARDOSO, Fernanda Serpa; YAMASAKI, Alice Akemi; BASTOS, Ana Luiza. Freire, Renzulli e as oficinas interativas para alunos superdotados. Educação em Foco, Juiz de Fora, v. 25, n. 3, p. 147-170, set. / dez 2020. Disponível em: https://periodicos.ufjf.br/index.php/edufoco/article/view/32923. Acesso em: 09 mar. 2021.

PÉREZ, Susana Graciela Pérez Barrera. Altas habilidades/superdotação e a política educacional: uma cronologia da história de letras no papel e omissões na prática. In: VIRGOLIM, Angela Magda Rodrigues. (org.). Altas habilidades/superdotação: processos criativos, afetivos e desenvolvimento de potenciais. Curitiba: Editora Juruá, 2018. p. 307 - 332.

PÉREZ, Susana Graciela Pérez Barrera. Mitos e Crenças sobre as Pessoas com Altas Habilidades: alguns aspectos que dificultam o seu atendimento. Revista Educação Especial, n. 22, p. 45-59, 2003. Disponível em: https://periodicos.ufsm.br/educacaoespecial/article/view/5004. Acesso em: 24 de mar. 2020.

PORTER, Michael Eugene. The Contributions of Industrial Organization to Strategic Management. The Academy of Management Review, [S.L.], v. 6, n. 4, p. 609, out. 1981. 


\section{RevistAleph}

REIMES, Fernando M. et al. Educação para o mundo do século 21: a criação de um curso de cidadania global. In: REIMES, Fernando M. et al. Empoderar crianças e jovens para a cidadania global: fundamentos e programa com atividades e referências, da educação infantil ao ensino médio. Tradução por: Danielle Salles. São Paulo: Moderna, 2017. p. 17 - 81.

RENZULLI, Joseph S. Expanding the Conception of Giftedness to Include Co-Cognitive Traits and to Promote Social Capital. Phi Delta Kappan, [S.L.], v. 84, n. 1, p. 33-58, set. 2002.

RENZULLI, Joseph S. Modelo de enriquecimento para toda a escola: um plano abrangente para o desenvolvimento de talentos e superdotação. Revista educação especial. [S.L.] v. 27, n. 50, 2014. Disponível em: https://periodicos.ufsm.br/educacaoespecial/article/view/14676. Acesso em: 03 de abr. 2020.

RIO DE JANEIRO. Secretaria de Estado de Educação. Currículo Mínimo 2012. Rio de Janeiro: SEEDUC, 2012.

ROTHBARD, Murray. Education: free and compulsory. Auburn: Ludwig von Mises Institute, 1999. Original em 1972.

SANTOS. Boaventura Sousa. Um discurso sobre as ciências. 6. ed. São Paulo: Cortez, 2009.

SETTON, Maria da Graça Jacintho. A teoria do habitus em Pierre Bourdieu: uma leitura contemporânea. Revista Brasileira de Educação, [S.L.], n. 20, p. 60-70, ago. 2002.

VIRGOLIM, Angela Magda Rodrigues. Altas habilidades/superdotação: encorajando potenciais. Brasília: Ministério de Educação, Secretaria de Educação Especial, 2007. Disponível em: http://www.dominiopublico.gov.br/download/texto/me004719.pdf. Acesso em: 17 de mar. 2020.

YAMASAKI, Alice Akemi. Violências no contexto escolar: um olhar freiriano. 2007. 220 f. Tese (Doutorado em Educação) - Faculdade de Educação, Universidade de São Paulo, São Paulo, 2007. 